\title{
ENTRE A SUBJETIVIDADE E A AUTOCRÍTICA: "ENTREVISTA NÃO DIRETIVA” E “HISTÓRIA ORAL” COMO POSSIBILIDADES DE PESQUISA QUALITATIVA EM CIÊNCIA POLÍTICA
}

\author{
Yuri Rodrigues Cunba ${ }^{1}$
}

\begin{abstract}
Resumo
O presente artigo tem por objetivo apresentar uma possibilidade teórico/metodológica para a pesquisa qualitativa em Ciências Sociais e Políticas privilegiando a perspectiva teórica marxiana, bem como a entrevista "não diretiva" e "história oral" como ferramentas importantes para a coleta dos dados qualitativos. Neste artigo parte-se da hipótese de que nas Ciências Sociais, é o sujeito/objeto de estudo que deverá indicar o método de coleta de dados a partir do questionamento proposto pelo pesquisador. Para avançar em direção ao objetivo e hipótese deste artigo o método empregado foi a análise bibliográfica acerca do tema proposto. Assim, através das análises aqui referenciadas, as principais conclusões que se chegou neste artigo, é que a subjetividade do pesquisador, que é construída historicamente, deve ser pensada com cuidado necessitando ser submetida às constantes autocríticas por parte do investigador.
\end{abstract}

Palavras-chave: pesquisa qualitativa; entrevista não diretiva; história oral; subjetividade do pesquisador; autocrítica.

\section{Resumen}

El presente artículo tiene como objetivo presentar una posibilidad teórico/metodológica para la pezquisa cualitativa en las Ciencias Sociales y Políticas privilegiando la perspectiva teórica marxista, así como la entrevista "no directiva" y "la historia oral" como herramientas importantes para la colecta de los datos cualitativos. En este artículo se parte de la hipótesis de que en las Ciencias Sociales, es el sujeto/objeto de estudios quien deberá indicar el método de colecta de datos a partir del cuestionamiento propuesto por el pesquisidor. Para avanzar en dirección al objetivo e hipótesis defendido en este artículo el método empleado fue el análisis bibliográfico acerca del tema propuesto. Así, a través de los análisis aquí referenciados, las principales conclusiones a que se llego en este artículo son: que la subjetividad del pesquisidor, que es construida históricamente, debe ser pensada con cuidado, necesitando ser sometida a las constantes autocriticas por parte del investigador.

Palabras-clave: pezquisa cualitativa; entrevista no directivo; historia oral; subjetividad de lo pesquisidor; autocritica

\begin{abstract}
The article aims to present a theoretical/methodological possibility for qualitative research in Social Science and Politics favoring the Marxian theoretical perspective, as well as "non-direct" interview and "oral history" like important tools for collecting qualitative data. This article proceeds on the assumption that in Social Science, the subject/object of study is that must indicate the method of data collection from proposed questioning by researcher. To move toward the goal and hypothesis of this article the method used was a literature review about the proposed theme. Thus, through the
\end{abstract}

\footnotetext{
${ }^{1}$ Mestrando em Ciências Sociais pela UNESP - Marília.
} 
analysis referenced here, the main conclusions have been reached in this article, is that the subjectivity of the researcher, which is historically constructed, should be considered carefully needing to be subjected to constant self-criticism on the part of the researcher.

Keywords: qualitative research; non-direct interview; oral history; subjectivity of the researcher; self-criticism

\section{INTRODUÇÃO}

Nas Ciências Sociais e Políticas a questão metodológica muitas vezes surge como um grande problema a ser enfrentado pelo pesquisador, isto porque, esta exige uma sensibilidade e responsabilidade do pesquisador em relação a seu objeto/sujeito de estudo. Sensibilidade se faz necessário na medida em que o fenômeno estudado não é estático, este - independente qual seja - está sempre em transformação, na medida em que faz parte de um processo social. Assim como a responsabilidade do pesquisador que se torna fundamental na medida em que este, ao adentrar no campo de pesquisa, exige-se uma postura ética, no sentido de uma autocrítica, bem como, a reflexão de sua interação com seu objeto/sujeito de pesquisa.

Convém destacar de antemão que neste trabalho o conceito de metodologia aqui empregado deve ser compreendido como o:

Estudo dos caminhos, dos instrumentos usados para se fazer ciência. [...] Ao mesmo tempo que visa conhecer caminhos do processo científico também problematiza criticamente, no sentido de indagar os limites da ciência, seja com referência à capacidade de conhecer, seja com referência à capacidade de intervir na realidade. (DEMO, 1995, p. 11)

$\mathrm{Na}$ avaliação aqui empregada refletir sobre metodologia é refletir sobre a própria práxis do cientista, o que tem por consequência levar em consideração os aspectos das técnicas de coleta dos dados, uma vez que, nas Ciências Sociais a investigação e o estudo de um determinado objeto, deve necessariamente passar pela maneira como o pesquisador irá coletar e lidar com os dados empíricos, para assim, tecer e apresentar os resultados desta pesquisa.

A metodologia seria a reflexão sobre o caminho ou caminhos seguidos pelo cientista em seu trabalho, nas diversas fases da proposição da pesquisa e de sua realização; em lugar de estar orientada por normas ou 
valores ideais, estaria orientada pela própria práxis, pela ação do cientista sobre a realidade. (QUEIROZ, 1991, p. 27).

Quando o pesquisador vai a campo e elabora a dimensão empírica de sua pesquisa, ele se depara com elementos inesperados, percebe que mesmo com todo o cuidado e pesquisa teórica, seu objeto mostra-se ainda mais complexo. Isso significa que com a dimensão empírica, a pesquisa não está totalmente nas mãos do pesquisador, é nesse momento que as hipóteses que norteiam seu trabalho serão testadas, e, por consequência, serão confirmadas ou não. Nesse sentido, deve o pesquisador ter claro suas intencionalidades, seu ponto de partida e onde quer chegar, todavia, este último não deve ser um elemento fixo, deve o pesquisador estar aberto e suscetível às influências não previstas que a pesquisa empírica revela.

Com isso, este artigo tem por objetivo apresentar ao leitor uma possibilidade teórico/metodológica de pesquisa qualitativa em Ciências Sociais e Políticas, onde, será exposta uma reflexão teórica sobre metodologia e o papel do pesquisador, e uma explanação metodológica pautada por duas diferentes - mas complementares - técnicas de pesquisa, a "história oral" e "entrevista não diretiva". Neste sentido, parte-se da hipótese de que nas Ciências Sociais e Políticas, é o objeto/sujeito de estudo que deverá indicar a técnica de coleta de dados a partir do questionamento proposto pelo pesquisador. Cabe ressaltar ainda que, este artigo faz parte de uma pesquisa de mestrado, cujos objetos/sujeitos de pesquisa são trabalhadores terceirizados que atuam no setor de limpeza em escolas públicas do município de Marília-SP, desenvolvido pela Faculdade de Filosofia e Ciências, UNESP, campi de Marília.

Para desenvolver o objetivo aqui apresentado, este artigo será dividido em três partes, além das considerações finais. No primeiro momento será apresentada uma elaboração teórica, cujo eixo condutor é levar o pesquisador a refletir sobre sua interação com seu objeto/sujeito de estudo, bem como quais suas intencionalidades ao delimitar um problema de pesquisa. No segundo ponto, serão apresentadas duas diferentes técnicas de coleta de dados empíricos, a "entrevista não diretiva", apresentada por Michelat (1980) e a "história oral" tal como evidenciada por Queiroz (1991; 1992). No terceiro tópico será exposta uma análise sobre a subjetividade, o papel do pesquisador e a necessidade de se buscar uma comunicação não-violenta, tal como exposto por Bourdieu (1997). Por fim, o artigo apresenta as considerações finais, no qual, busca-se retomar a hipótese deste trabalho. 


\section{ORIENTAÇÕES TEÓRICAS: A RELAÇÃO ENTRE O PESQUISADOR E SEU OBJETO/SUJEITO DE ESTUDO}

Delimitar um tema para a pesquisa nas Ciências Sociais exige-se do pesquisador o reconhecimento de sua inserção em um universo físico, social e intelectual, assim, é por meio da percepção e interação com este universo que formula o problema que busca investigar (QUEIROZ, 1991; 1992). Assim, realizar um trabalho sociológico é necessário que o pesquisador possua uma formação específica que permita reconhecer a tomada consciente de sua posição, levando em consideração o conjunto de conhecimentos produzidos e acumulados pela ciência em questão, compreendendo a dimensão socioeconômica e histórica do fenômeno a ser investigado.

Nesse sentido o pesquisador deve reconhecer que está imerso em um contexto histórico e seus desejos e aspirações são produtos de sua interação com o meio social que o rodeia. Deve compreender que suas ações nunca são vazias e/ou alheias, assim, "a reflexão de sua própria posição é indispensável” (QUEIROZ, 1992, p.19), ou seja, o pesquisador deve também levar em consideração que em seu objeto/sujeito de estudo contém suas próprias intencionalidades (Kosik, 1986), e que, seus objetivos são construídos segundo sua consciência social e visão de mundo, construídos através de sua experiência (THOMPSON, 1981).

De acordo com a avaliação de Queiroz (1992), para se elaborar um problema de pesquisa, deve o pesquisador, reconhecer que o campo epistemológico no qual se insere possui um corpus teórico pré-existente, e que, o investigador deve abarcar na maior amplitude possível a compreensão das diversas posturas teóricas fundamentais, além das teorias específicas ligadas ao problema que pretende investigar. Ainda segundo a autora, na medida em que o pesquisador conhece o grupo em particular que pretende estudar, e quanto for maior sua familiaridade com este grupo, torna-se mais fácil formular o problema, ao mesmo tempo em que, a análise ganha em sutileza e agudez (QUEIROZ, 1991). Em outras palavras, "quanto mais abrangente e mediado for o assunto escolhido, mais óbvio deverá ser seu vínculo com as determinações estruturais "totalizadoras" da época histórica relevante” (MÉSZÁROS, 2009, p. 17).

Com isso, é possível retomar uma ideia desenvolvida por Weber, onde afirma que realizar uma pesquisa em Ciência Política depende do caráter subjetivo do pesquisador, bem como qual relação possui com o objeto/sujeito pesquisado, dito de outra maneira, a 
escolha de um objeto depende da vontade do pesquisador em investigar determinado fenômeno.

O caráter de fenômeno "socioeconômico" de um evento não é algo que lhe seja "objetivamente" inerente. Pelo contrário, ele está condicionado pela orientação do nosso interesse de conhecimento, e essa orientação define-se conforme o significado de cultura que atribuímos ao evento em questão em cada caso particular. Sempre que um evento da vida cultural vinculase direta ou indiretamente aquele fato básico, através daqueles elementos da sua especificidade nos quais repousa para nós o seu significado próprio, ele contém ou pelo menos pode conter, [...] um problema de ciência social (WEBER, 2003, p. 79; grifo nosso).

Levar em consideração a subjetividade do pesquisador não significa que ela esteja "pairando no ar", mas que, se constitui na prática (SILVEIRA, 1989), e por isso representa elementos da cultura, valores morais e éticos. Assim "o campo da subjetividade engloba o conjunto dos processos pelos quais o indivíduo, em estreito contato com as estruturas simbólicas da cultura humana, tenta assumir e abrir um acesso à forma genérica de seu ser" [DORAY, 1989, p. 85, grifos no original]. Isto significa que o pesquisador ao delimitar um objeto/sujeito de pesquisa, deve compreender que esta escolha está umbilicalmente ligada ao interesse do proponente da investigação, e esta orientação se dá através de suas inclinações teóricas e ideológicas para investigar o fenômeno proposto. Nesse sentido, cabe identificar a perspectiva teórica na qual a pesquisa que embasa este artigo se orienta. O trabalho que serve de base para a elaboração deste artigo parte de uma perspectiva marxiana ${ }^{2}$, e este deve conter os elementos identificados por Mészáros como o "radicalismo metodológico", no qual o pesquisador não deve perder de vista a transformação da sociedade.

Com isso, um pressuposto básico para uma análise metodológica no campo marxiano é o diálogo entre dimensões teórica e empírica, uma vez que estas não se separam e constitui uma unidade, uma práxis; isso significa que com esse viés metodológico, o

\footnotetext{
2 A escolha por esta perspectiva teórica se dá na medida em que a própria biografia do autor do artigo em questão e sua militância política, o aproximou do campo teórico do marxismo. Porém, isto não significa que seja "a" perspectiva teórico/metodológica mais viável, mas se apresenta como um dos métodos desenvolvidos historicamente pelas Ciências Sociais.

3 "O radicalismo metodológico da abordagem marxiana e sua importância para a época em que se originou são determinadas pela profunda crise de uma ordem social cujos problemas só podem ser solucionados por uma reestruturação radical da própria ordem social, nas suas dimensões fundamentais. [...] Naturalmente, a realização de uma reestruturação radical da sociedade é inconcebível com um "acontecimento" repentino e irreversível. Ela deve ser encarada, em vez disso, como um processo auto-renovador, mantido por um período histórico tão longo quanto persistir sua necessidade em relação a determinadas tarefas e a adversários ideológicos bem identificados.” (MÉSZÁROS, 2012, p. 307).
} 
pesquisador não deve perder a dimensão da transformação da sociedade capitalista, uma vez que, é na práxis que deve estar a criteriosidade desse pensamento.

A questão se cabe ao pensamento humano uma verdade objetiva não é teórica, mas prática. É na práxis que o homem deve demonstrar a verdade, a saber, a efetividade e o poder, a criteriosidade de seu pensamento. A disputa sobre a efetividade ou não-efetividade do pensamento-isolado da práxis - é uma questão puramente escolástica (MARX, 1978, p. 51 grifos no original.

Reconhecer o processo histórico, identificar contradições, buscar mediações necessárias para as transformações, não são processos simples, exigem tempo. O processo histórico pode ser considerado árduo, pois se faz no cotidiano, nas potencialidades geradas através do trabalho, e também, exigem maiores esforços para as transformações sociais. Com isso, destaca-se que se "é na práxis que o homem deve mostrar a [...] criteriosidade do seu pensamento (MARX, 1978, p. 51)”, esta forma de atuação é contínua, pois é no cotidiano ${ }^{4}$ que são criadas as possibilidades revolucionárias, possibilitando que a práxis se eleve e supere a cotidianidade ${ }^{5}$ (HELLER, 1985).

Utilizar esse método inaugurado por Marx é estar sujeito a erros e acertos, pois está sujeito aos limites teóricos de quem elabora a pesquisa, bem como, também depende da capacidade do pesquisador em partir da realidade concreta, submeter ao pensamento abstrato, e retornar ao concreto, como concreto pensado (MARX, 2011). Isso significa compreender a totalidade das relações sociais e depende, sobretudo, da perspicácia do pesquisador. Nesse sentido, deve-se sempre partir das relações concretas da produção material histórica, a qual é socialmente determinada, ou seja, o sujeito produzindo em sociedade (MARX, 2011). Somente a partir dessas relações poder-se-á ir desdobrando para outras dimensões, "por essa razão, o concreto aparece no pensamento como o processo da

\footnotetext{
${ }^{4}$ Nas Ciências Sociais há um profuso debate acerca do cotidiano, para Lefebvre (1984) a concepção de cotidiano só tem consistência se levado em conta as contradições do processo histórico, o cotidiano como contraponto (e alienação) da história, por isso mesmo, o cotidiano não tem sentido se divorciado do processo histórico que o reproduz. Com isso, é possível afirmar que não há, para Lefebvre, reprodução sem uma certa produção de relações sociais, não há cotidiano sem história.

${ }^{5} \mathrm{Na}$ avaliação de Heller (1985) a vida cotidiana é a vida do homem inteiro, isto é, o homem participa na vida cotidiana com todos os aspectos de sua individualidade e de sua personalidade. Porém, mesmo o homem do cotidiano sento atuante e fruidor, ativo e receptivo ele não é capaz de se absorver em nenhum desses aspectos, o que implica que o pensamento cotidiano orienta-se para a realização de atividades cotidianas, e em certa medida como pensamento imediato para ação imediata. Em certo sentido, o pensamento no cotidiano apresenta-se repleto de pensamentos fragmentários, e isso gera o que a autora compreende por cotidianidade, isto é, na cotidianidade o conhecimento se limita ao aspecto relativo da atividade, e por isso mesmo é a esfera que mais se presta a alienação.
} 
síntese, como resultado, não como ponto de partida, não obstante seja o ponto de partida efetivo e, em consequência também o ponto de partida da intuição e da representação (MARX, 2011, p. 54)".

Nesse sentido é possível afirmar que, o pesquisador está intimamente ligado ao seu objeto/sujeito de estudo, na medida em que determina o objeto/sujeito a ser estudado de acordo com seus interesses, e também, com sua relação com este. Levar em consideração estes elementos, assim como se concebe neste artigo não é um problema, diferente do que sugere Durkheim (2007) com seu método positivista. Pois de acordo com este método o pesquisador deve manter-se distante do seu objeto de estudo para que, através de sua neutralidade possa alcançar uma maior objetividade ${ }^{6}$.

Assim, Durkheim não entende que ambos, pesquisador e objeto, fazem parte de um tecido social, no qual estão imersos, no entanto, na análise aqui realizada, é impossível de separar os dois. É importante ressaltar que a separação entre pesquisador e objeto enquanto requisito para a produção de uma "ciência", verdadeira, neutra e objetiva, possui interesses ideologicamente orientados. Isto porque, separá-los, é justamente retirar o que há de mais importante na pesquisa em Ciências Sociais e Políticas, ou seja, o caráter histórico e dinâmico dos processos sociais. Nesse sentido "em lugar da dialética histórica das inter-relações sociais complexas, ele [positivismo] oferecia a objetividade fetichista de grosseiras determinações materiais e instrumentais” (MÉSZÁROS, 2012, p 255).

Deve ser ressaltado que apesar da crítica a objetividade no sentido positivista, é importante o pesquisador ter em mente que a na produção do conhecimento científico a objetividade é necessária. Assim, a objetividade só pode ser alcançada se reconhecer que esta é em última instância prática e histórica. Isto significa que, a relação pesquisador e sujeito/objeto de pesquisa não é uma relação externa, mas sim, uma relação no qual o sujeito pesquisador está implicado em seu objeto, e somente assim entende-se neste artigo, que é possível a objetividade. Essa característica não exclui a objetividade do conhecimento teórico, mas sim, leva em consideração as tendências históricas através das práticas sociais (NETTO, 2011). Com isso, não é possível pensar uma objetividade sem levar em conta o caráter relacional e histórico do homem e da natureza, do sujeito e do objeto, das relações dos sujeitos entre si e consigo mesmo em meio à sociedade. Dito de outra maneira, a

\footnotetext{
6 "É preciso, portanto, que o sociólogo, tanto no momento em que determina o objeto de suas pesquisas, como no curso de suas demonstrações, proíba-se resolutamente o emprego daqueles conceitos que se formaram fora da ciência e por necessidades que nada tem de científico. É preciso que se liberte dessas falsas evidências que dominam o espirito do vulgo, que se livre, de uma vez por todas, do jugo dessas categorias empíricas que um longo costume acaba geralmente por tornar tirânicas." (DURKHEIM, 2007, p. 32 - 33 grifo nosso).
} 
objetividade não é possível sem a correspondência com a subjetividade e os interesses do pesquisador, isto quer dizer que o pesquisador tem seus interesses na medida em que é um sujeito que se constrói historicamente nas relações sociais, e, portanto, seus interesses e sua subjetividade deve ser estar historicamente localizada.

A objetividade na história é impensável sem uma íntima correspondência com a subjetividade. Não há objeto sem sujeito, assim como não há sujeito sem objeto. Para dizer melhor, as objetivações e as subjetivações que lhes correspondem são dimensões cardeais que fazem da práxis histórica uma práxis humana; condição mesma para que o bistórico seja absolutamente inseparável do bumano. (SILVEIRA, 1989, p. 12)

Portanto, reconhecer o corpus teórico tal como fala Queiroz (1991; 1992) é também lidar com o que motiva o pesquisador a elaborar seu problema de pesquisa. Com isso, destaca-se que a reflexão entre o método escolhido pelo pesquisador, bem como, sua interação com o sujeito/objeto de pesquisa, e suas intencionalidades, é considerada aqui, como um elemento fundamental, um princípio ético, no qual o pesquisador deve se submeter, como uma espécie de autocrítica. Toda essa discussão apresentada, mas, sobretudo, a autocrítica do pesquisador tem um elemento fundamental para este artigo, a reflexão sobre a subjetividade do pesquisador ${ }^{7}$ o que irá evidenciar o preparo deste ao desenvolver sua pesquisa.

Portanto, para o pesquisador reconhecer seu ponto de partida, e aonde quer chegar com sua pesquisa é primordial para delimitar as técnicas que serão empregadas para a coleta de dados empíricos, caso seja necessário na pesquisa. Como já foi dito anteriormente, neste artigo parte-se de uma pesquisa de mestrado, cujos sujeitos de pesquisa são trabalhadores terceirizados que atuam no setor de limpeza em escolas públicas no município de Marília-SP. O objetivo que foi buscado pelo pesquisador era apresentar de que maneira este trabalho precário e instável, pela própria natureza jurídica que o rege, precariza a vida do sujeito exposto a tal trabalho, e também, como esta impacta a vida objetiva e subjetiva deste trabalhador.

Assim, ao realizar este recorte, a pesquisa de campo, através da entrevista tornou-se um elemento central. Porém, outra dificuldade fora posta, como captar essa sutileza da vida do sujeito trabalhador, sem cometer uma comunicação "não violenta" (BOURDIEU, 1997). Dito de outra maneira, como deveria o pesquisador se lançar a campo, procurar trabalhadores terceirizados, realizar entrevistas, onde deveria tocar em

\footnotetext{
${ }^{7}$ Este elemento será retomado mais adiante.
} 
assuntos que poderiam causar dor ao sujeito depoente? Além disso, qual seria o melhor método na coleta de dados para tentar alcançar o objetivo proposto pela pesquisa, entrevista dirigida, semi-estruturada ou não diretiva? Com isso, através da reflexão teórica, chegou-se a duas técnicas que se mostravam bastante parecidas, e que, se mostravam eficientes para captar em profundidade elementos que os entrevistados e depoentes estivessem dispostos a falar.

\section{MÉTODOS PARA A COLETA DE DADOS EMPÍRICOS: ENTREVISTA NÃO DIRETIVA E HISTÓRIA ORAL}

Para investigar uma determinada política, pode-se abarcar sua área de abrangência, compreendendo, por exemplo, a quantidade de sujeitos que esta alcança, no sentido quantitativo. Porém, neste artigo, o foco é a profundidade, ou seja, mais do que captar e compreender os elementos quantitativos da Ciência Política chama-se a atenção para a profundidade, ou seja, de que maneira os sujeitos são influenciados pela política, e em que medida esta modifica a vida objetiva e subjetiva destes. Nesse sentido, a pesquisa qualitativa, com entrevista "não diretiva" e "história oral", mostram-se duas técnicas propícias para que possa captar estas mudanças.

Retomando a concepção de Netto (2011), para a qual é a estrutura e a dinâmica do objeto/sujeito que deve nortear os procedimentos do pesquisador que a nosso ver parte sempre do questionamento do pesquisador, e, levando em consideração a proposta deste artigo, a pesquisa empírica deve buscar as experiências vividas pelos sujeitos e como estes observam e enxergam a realidade ao seu redor. Porém, esta busca é complexa na medida em que, deve-se reconhecer que o entrevistado possui uma história de vida, uma formação integral específica, ou seja, é um sujeito singular. Nesse sentido, ao levar isso em consideração, as técnicas de coleta de dados através da entrevista "não diretiva" e a "história oral" foram os métodos encontrados pelo autor que possibilita captar informações que só podem ser expostas pelo sujeito depoente, e não através de questionário estruturado previamente.

Combinar diferentes técnicas de entrevista, e abrir mão de um questionário estruturado e/ou semiestruturado tem um sentido bem claro para o autor deste artigo, na medida em que, o questionário estruturado não possibilita uma investigação em maior profundidade. Isto quer dizer que, se impõe limites ao entrevistado, na medida em que, o questionário delimitado de antemão pelo pesquisador está fechado, ou seja, não permite 
uma maior interferência do sujeito entrevistado, uma vez que este está ocupado em responder apenas o que foi perguntado. A este cabe apenas responder as perguntas préestabelecidas, ao passo que na entrevista "não-diretiva" "o entrevistado talvez coloque problemas em termos completamente diferentes dos que o pesquisador imagina" (MICHELAT, 1980, p. 193).

Além disso, um questionário fechado traz limites na medida em que, para o pesquisador, a pesquisa de campo é algo cumulativo, assim, o próprio pesquisador já não é o mesmo depois da primeira entrevista, e que também será diferente após a segunda, etc.. Neste sentido, a pesquisa "é um processo acumulativo, que resulta da escuta atenta e da reflexão sobre as informações que vão sendo coletadas, e que implicam em novos questionamentos nas entrevistas subsequentes" (DAMARTINI, 1992, p. 45).

Com relação à entrevista não diretiva é importante ressaltar alguns pontos importantes. Destarte, cabe lembrar que estas técnicas de coletas de informações são métodos complementares não podendo substituir outros métodos de coleta de informação, ou uma entrevista diretiva (MICHELAT, 1980). De igual maneira, a história oral recobre uma quantidade de relatos a respeito de fatos não registrados por outro tipo de documentação, portanto, a história oral não pode ser um fim em si mesmo, uma vez que o pesquisador pode colher dados de fontes das mais variadas, quando quer abarcar de forma mais ampliada à realidade que estuda (QUEIROZ, 1991).

Antes de apontar com maiores detalhamentos estas duas técnicas faz-se necessário que ao utilizá-las, busque objetivos específicos e questões que envolvem o sentir e a experiência do sujeito entrevistado. $\mathrm{O}$ sujeito, por ser historicamente determinado e culturalmente situado, portanto portador de culturas e também representativo delas, ao ser interrogado de maneira não-diretiva, possibilita a emergência do conteúdo sócio-afetivo profundo, facilitando ao entrevistador o acesso às informações que não podem ser atingidas diretamente (MICHELAT, 1980).

De maneira semelhante, a história oral pode captar a experiência efetiva dos narradores, recolhendo, também, tradições, mitos, narrativas de ficção e crenças existentes no grupo (QUEIROZ, 1991). Ainda de acordo com a autora, o relato oral constituíra sempre a maior fonte humana de conservação e difusão do saber, e em todas as épocas, a educação humana se baseara na narrativa, que transpõe a experiência indizível traduzida em vocábulos (QUEIROZ, 1991). Portanto, na história oral, a coleta de dados deve centrar-se na experiência do trabalhador, por isso, é de suma importância buscar compreender quem é 
este sujeito, seus trajetos de vida que o levaram até o momento da entrevista, quais são suas angústias, de que maneira as políticas investigadas pelo pesquisador afetam e como afetam a vida destes, e não só no momento mais imediato, mas também, em planos futuros, ou seja, é levar em consideração o ser humano em seu aspecto mais pleno.

Nesse sentido, estas técnicas possibilitam maior liberdade ao entrevistado, facilitando a produção de informações sintomáticas que correriam o risco de serem censuradas em outro tipo de entrevista, sobretudo a fechada ou diretiva. Com isso, destacam-se os princípios destas técnicas adotadas nesta pesquisa:

$\mathrm{Na}$ entrevista não-diretiva, procura-se fazer com que a pessoa entrevistada assuma o papel de exploração habitualmente detido pelo entrevistador; este último então não desempenha mais um papel de facilitação e de apoio. Parte-se da ideia de que a pessoa interrogada é a mais apta a explorar o campo do problema que lhe é colocado, em função do que ela pensa e sente. Isto deve corresponder a uma aceitação real, pelo entrevistador, da pessoa interrogada tal como ela é (MICHELAT, 1980, p. 191 grifo nosso)

Neste sentido, deve-se reconhecer que o entrevistado também detém a atitude de exploração (MICHELAT, 1980), com isso, é importante destacar um aspecto sugerido por Sato e Souza (2001), ao afirmarem que delimitar um objeto/sujeito de pesquisa, e optar por um determinado método que exige a entrada no campo, corre-se o risco do sujeito pesquisador colocar os outros, as pessoas do local como o "objeto" a ser pesquisado, e não um sujeito ativo no processo de pesquisa. Nesse sentido, para os autores referidos, ambos são pesquisadores, entrevistador e entrevistado.

Para as pessoas do local interessa saber quem somos, porque nos interessamos por conhecê-las, por conhecer seu dia-a-dia, os jeitos de se comportar e se relacionar; interessa também saber qual a utilidade benéfica ou maléfica - que nossa pesquisa terá; qual a nossa real intenção, não expressa; como pesquisamos: com questionários, com perguntas também se mostram curiosos para saber se escreveremos um livro [...] e, sobretudo, interessa também saber quem somos, o que fazemos, como vivemos. Assim, o fornecimento e o ocultamento de informações ao pesquisador serão controlados pelas representações que essas pessoas criam sobre "quem é o pesquisador". (SATO, SOUZA, 2001, s.p.)

Por fim, após apresentado ainda que de maneira breve as duas técnicas, evidenciando quais são suas preocupações, deve-se ainda apontar a maneira como se realiza a análise desses dados coletados. Uma vez que ambas as técnicas de entrevistas não privilegiam o questionário fechado, e portanto as entrevistas podem e quase sempre tomam 
caminhos distintos, a perspicácia do pesquisador deverá ser explorada. Após realizar as entrevistas, deve ainda o pesquisador transcrever os áudios, uma tarefa bastante trabalhosa, mas que no momento em que se fazem estes trabalhos o pesquisador ouve novamente as entrevistas. Nestes momentos costumam surgir insights que ajudarão na análise, na medida em que estas apreciações devem ser submetidas às análises teóricas da bibliografia utilizada para embasar teoricamente a pesquisa.

Outro passo importante para a análise dos dados é subdividir trechos das entrevistas agrupando em eixos temáticos para o qual o pesquisador quer chamar a atenção, por exemplo, gênero, etnia, etc. Essa prática não deve ser realizada com um sentido quantitativo, ou seja, quantas vezes aparecem tal conceito, ou determinada palavra, mas agrupar para perceber como estes elementos estão presentes na vida dos sujeitos pesquisados. Dito de outra maneira é com esse agrupamento que o pesquisador conseguirá tecer a sua produção teórica na medida em que protagoniza o sujeito entrevistado.

Portanto, conclui-se que, os dois métodos privilegiados por este artigo, entrevista não diretiva e história oral, permitem que não só o pesquisador seja responsável por sua pesquisa, mas também, permite identificar que o sujeito entrevistado ocupe um papel central, ou seja, é este que vai determinar o que será dito, o que deve ser revelado, cabendo ao pesquisador, submeter à análise o que foi exposto pelo entrevistado. A análise que o pesquisador irá realizar deve ir ao encontro do próprio objetivo de pesquisa, refutando ou não sua hipótese de pesquisa.

\section{A COMUNICAÇÃO NÃO VIOLENTA E A SUBJETIVIDADE DO PESQUISADOR}

Nesse momento é necessário discutir mais um elemento de grande importância para o autor deste artigo. Reconhecer o entrevistado como um sujeito, e não só como objeto de pesquisa, deve-se levar em consideração a maneira como o pesquisador se insere no campo de pesquisa, como este busca uma comunicação que não seja violenta, ou seja, deve o pesquisador refletir e buscar uma maneira que diminua os efeitos de sua entrada arbitrária no campo de pesquisa.

Essa reflexão proporcionada por Sato e Souza (2001), permite uma aproximação da entrevista "não-violenta" da qual fala Bourdieu (1997), na medida em que o pesquisador deve tentar conhecer os efeitos que se podem produzir no depoente ou 
entrevistado, através de sua entrada "arbitrária" no campo. Com isso, deve também o pesquisador

Tentar esclarecer o sentido que o pesquisado se faz da situação, da pesquisa em geral, da relação particular na qual ela se estabelece, dos fins que ela busca e explicar as razões que o levam a aceitar de participar da troca. É efetivamente sob a condição de medir a amplitude e a natureza da distância entre a finalidade da pesquisa tal como é percebida e interpretada pelo pesquisado, e a finalidade da pesquisa tal como é percebida e interpretada pelo pesquisado, e a finalidade que $\mathrm{o}$ pesquisador tem em mente, que este pode tentar reduzir as distorções que dela resultam, ou, pelo menos, de compreender o que se pode ser dito e o que não pode, as censuras que o impedem de dizer certas coisas e as incitações que encorajam a acentuar outras. (BOURDIEU, 1997, p. 695).

Todas estas reflexões aqui levantadas têm um sentido de possibilitar uma "reflexividade" tal como definida pela "sociologia reflexiva", mas sem criar um fim em si mesmo. Com isso, destaca-se a necessidade de pensar em um relativismo cultural por parte do pesquisador, cuja "imaginação sociológica" não ultrapassa o campo mental de seu próprio meio social (THIOLLENT, 1980). Portanto, a autocrítica mais uma vez deve ganhar papel de destaque nas preocupações do pesquisador.

Outro problema a ser enfrentado em pesquisas não-diretivas e pela história oral são as diferenças culturais, e os desníveis de compreensão ou comunicação entre esses polos, porém, isso não significa que exista uma relação hierárquica entre os saberes, deve haver nesse sentido, uma troca de saberes (FREIRE, 1989), na medida em que a dimensão da práxis está sempre presente com o pesquisador.

Mesmo com a preocupação e o cuidado do pesquisador, ao utilizar as técnicas de coleta de dados através da história oral e entrevista não diretiva, no qual se busca levar em consideração os sujeitos entrevistados como membros ativos do processo de pesquisa, não se deve ter a ingênua concepção de que estas técnicas são ideais, pois, ambas ainda produzem "a mesma separação entre o analista e os analisados" (THIOLLENT, 1980, p. 83).

Toda essa exposição deságua em uma relação de grande importância para o autor deste artigo: a reflexão sobre a subjetividade do pesquisador e a necessidade de uma autocrítica para assim, possibilitar avanços tanto no conhecimento do objeto de estudo, quanto na possibilidade de uma atuação em um sentido da práxis. Levar em consideração a

\footnotetext{
8 A entrada arbitrária é percebida, e visto sob a ótica do entrevistado ou depoente, uma vez que para o pesquisador essa entrada a campo não é arbitrária, pois este já refletiu sobre "qual" campo adentrar.
} 
subjetividade do pesquisador não significa imergir em um mundo inacessível, mas é reconhecer que "a subjetividade do pesquisador apresenta uma base coletiva" (KOSMINSKY, 1999, p. 78). Dito de outra maneira, a subjetividade não é pensada como sendo posta naturalmente como uma essência interior, mas "se constitui na e pela prática" (SILVEIRA, 1989, p. 46).

Isso significa que a relação sujeito-objeto está centrada nos interesses do pesquisador, e por tratar-se de seres humanos, inseridos em estruturas sociais e culturais, historicamente determinadas, o pesquisador corre o risco de fechar-se em torno das perspectivas teóricas adotadas, utilizando dados do concreto e do real apenas para comprovar suas hipóteses e suas elaborações teóricas, retirando o caráter processual e histórico das relações sociais. Para que a subjetividade do pesquisador não seja prejudicial, mas que se torne possível para uma melhor compreensão da realidade faz-se necessário uma constante autocrítica do pesquisador, reiterando assim, o seu enunciado a respeito de seu preparo através de uma autoanálise (KOSMINSKY, 1999).

A atitude do homem, em face da realidade, não é a de um abstrato sujeito cognoscente, de uma mente pensante que examina a realidade especulativamente, porém a de um ser que age objetiva e praticamente, de um indivíduo histórico que exerce a sua atividade prática no trato com a natureza e com os outros homens, tendo em vista a consecução dos próprios fins e interesses. (KOSIK, 1976, p. 9)

Isso significa que a autocrítica possui um papel-chave, na medida em que permite um "aprofundamento teórico quanto para possibilitar ao movimento social do proletariado superar as inevitáveis contradições e as falhas de sua realização prática" (MÉSZÁROS, 2012, p. 315). Entende-se aqui que a autocrítica possui um valor ético ${ }^{9}$ para o pesquisador, na medida em que se refere tanto ao senso moral - concebido como costumes socialmente construídos -, bem como a uma consciência individual - o caráter, a índole -, ou seja, o

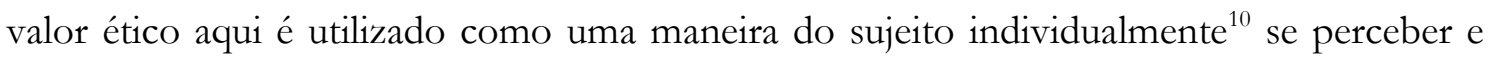
lidar com as relações sociais historicamente determinadas.

\footnotetext{
${ }^{9}$ Ética deriva do grego Éthos ( $\eta$ Oos), que pode ser traduzido de modo geral como caráter, atitude, conduta, costume, moral (Miniatoglou, 2004). De acordo com Chauí (2000), o termo Éthos/Êthos, no grego possui duas vogais para pronunciar e grafar a vogal $e$ : êthos (com com vogal breve e fechada, épsilon, $\varepsilon, \varepsilon \theta o \varsigma$ ), que significa caráter, índole natural, temperamento; enquanto que éthos (com vogal longo e aberto, $\eta, \eta \theta 0 \varsigma$ ) significa costume.

${ }^{10}$ Nunca é demais ressaltar que esse "sujeito individual" é socialmente concebido, em outras palavras, o sujeito se constitui como sujeito em meio à sociedade onde está inserido, portanto, nunca isoladamente.
} 
Desta maneira, a forma de coleta e obtenção de dados, engloba o "questionamento" atividade metodológica e epistemológica, que deve acompanhar o desenrolar da pesquisa científica. Assim, o "questionamento sociológico"12 pode ser definido como um modelo de pesquisa e deve possibilitar um diálogo entre o polo investigador e o polo investigado, e em diversas formas de pesquisa-ação (THIOLLENT, 1980).

\section{CONSIDERAÇÕES FINAIS}

Portanto toda essa discussão acerca de uma possibilidade de método para a coleta de dados, no qual, a busca por uma comunicação não violenta onde o sujeito pesquisado faça parte também como pesquisador, posto que este também investiga a postura do pesquisador e como este chegou até si, é importante para captar qualitativamente como uma determinada relação é observada pelos sujeitos inseridos nesse contexto, por exemplo, captar as relações de trabalho e emprego, captar o alcance e profundidade de uma determinada política pública, etc. Nesse sentido, deve buscar-se ir além da "pseudoconcreticidade" (KOSIK, 1986), ou seja, investigar o que não é aparente, e assim, buscar a relação com uma totalidade social a partir de um dado concreto.

Com isso, destaca-se que o processo de investigação deve partir da realidade concreta, no sentido atribuído por Marx, para o qual, “o concreto é concreto porque é a síntese de múltiplas determinações, portanto, unidade da diversidade” (MARX, 2011, p. 54). Assim como afirma Thompson (1981) a experiência é necessária quando se investiga fenômenos históricos inter-relacionados, ou seja, deve-se olhar também para as tensões sociais, para as práticas cotidianas, ampliar a visão para as múltiplas evidências. Levar em consideração estas ideias é reconhecer também que os homens fazem sua própria história.

Nesse sentido, retoma-se a hipótese deste artigo para o qual, deve ser o objeto/sujeito de pesquisa que deverá indicar a técnica para a coleta e forma de análise dos

\footnotetext{
${ }^{11}$ Michel Thiollent [1980: p. 24] subdivide-se o conceito “questionamento” em quatro níveis de aplicação: a) o questionamento da obtenção de dados, b) o questionamento das convencionais técnicas de pesquisa, c) o questionamento dos pressupostos, das categorias e de outros elementos relativos à visão do mundo dos sociólogos que são aplicadas, em geral, de modo implícito, na concepção da investigação, na formulação de questionários, etc., e d) o questionamento sociológico enquanto substituto da observação. Para Thiollent esses quatro níveis são relacionados uns com os outros, por isso aqui, optou-se por utilizar o conceito "questionamento sociológico", pois ao utilizá-lo necessariamente deve-se ter em mente as outras três perspectivas.

12 "Sob constante controle metodológico operando aos três níveis de questionamento, o questionamento sociológico, depende de uma problemática teórica, consiste na investigação da realidade social por meio de um sistema de perguntas e de respostas que circulam dentro da rede comunicacional que envolve o relacionamento entre o polo investigador e o polo investigado" (THIOLLENT, 1980, p. 25)
} 
dados, tendo em vista o questionamento enunciado pelo pesquisador. Isso significa que ao buscar responder os questionamentos que o guiam, cabe ainda ao pesquisador estar "aberto" as determinações de seu objeto de pesquisa. Isto é, o pesquisador não desprezar de antemão nenhum método de pesquisa e/ou técnica de coleta de dados, isto porque, cada uma das técnicas de pesquisa como a análise documental, pesquisa bibliográfica, entrevistas estruturada, semi-estruturada, e não diretiva, têm suas funcionalidades e dão conta de responder determinados questionamentos. Porém, deverão ser todos submetidos a uma avaliação constante e uma necessária autocrítica do pesquisador, no qual deve ser claro para este quais suas intencionalidades ao lidar com seu sujeito e/ou objeto de pesquisa.

\section{REFERÊNCIAS BIBLIOGRÁFICAS}

BOURDIEU, P. 1997. Compreender. In: BOURDIEU, P. et al. A Miséria do Mundo. Petrópolis: Vozes, p. $693-713$.

DAMARTINI, Z. B. F. 1992. Trabalhando com Relatos Orais: reflexões a partir de uma trajetória de pesquisa. In: In: LANG, A. B (org.). Reflexões Sobre a Pesquisa Sociológica. São Paulo: CERU, p. $42-60$.

DEMO, P. Metodologia Científica em Ciências Sociais. São Paulo: Atlas, 1995.

DORAY, B. 1989. Da produção à subjetividade: referencias para uma dialética das formas. In: SILVEIRA, P; DORAY, B. (orgs.). Elementos Para uma Teoria Marxista da Subjetividade. São Paulo: Vértice, p. 77 - 108.

DURKHEIM, E. 2007. As Regras do Método Sociológico. $3^{\text {a} E d . ~ S a ̃ o ~ P a u l o: ~ M a r t i n s ~ F o n t e s . ~}$ FREIRE, P. 1989. Educaşão Como Prática de Liberdade. Rio de Janeiro: Paz e Terra.

HELLER, A. 1985. O Cotidiano e a História. 2a . ed. . Rio de Janeiro: Paz e Terra.

KOSIK, K. 1986. Dialética do Concreto Rio de Janeiro: Paz e Terra.

LEFEBVRE, H. 1984. La Vida Cotidiana en el Mundo Moderno. Madrid: Alianza Editorial.

MARX, K. 1978. Teses Contra Feuerbach. In: Os Pensadores. São Paulo: Abril Cultural.

$2^{\mathrm{a}}$ Edição, p. 49 - 55.

MARX, K. 2011. Grundrisse: manuscritos econômicos de 1857 - 1858: esboços da crítica da economia política. São Paulo: Boitempo. 
MÉSZÁROS, I. 2009. Estrutura Social e Formas de Consciência: a determinação social do método.

São Paulo: Boitempo. 2012. O Poder da Ideologia. São Paulo: Boitempo.

MICHELAT, G. 1980. Sobre a utilização da entrevista não-diretiva em sociologia. In: THIOLLENT, M. Crítica Metodológica, Investigação Social e Enquete Operária. São Paulo: Pólis, p. $192-211$.

NETTO, J. P. 2011. Introdução ao Estudo do Método de Marx São Paulo: Expressão Popular.

QUEIROZ, M. I. P. de. 1991. Variações Sobre a Técnica de Gravador no Registro da Informação Viva. São Paulo: T.A. QUEIROZ, 1992. O Pesquisador, o problema da pesquisa, a escolha de técnicas: algumas reflexões. In: LANG, A. B (org.). Reflexões Sobre a Pesquisa Sociológica. São Paulo: CERU, p. $13-29$.

THOMPSON, G. P. A. 1981. Miséria da teoria ou um planetário de erros. Rio de Janeiro: Zahar. THIOLLENT, M. 1980. Crítica Metodológica, Investigação Social e Enquete Operária. São Paulo: Pólis.

SATO, L; SOUZA, M. P. R. 2001. Contribuindo para Desvelar a Complexidade do Cotidiano através da Pesquisa Etnográfica em Psicologia. Psicol. USP, São Paulo, v. 12, n. 2. Disponível em <http://www.scielo.br/scielo.php?script=sci $\operatorname{arttext\& pid=S0103-}$

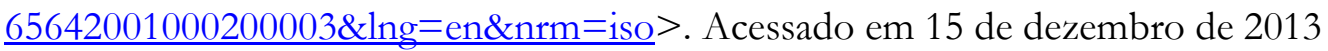

SILVEIRA, P. 1989. Apresentação. In: SILVEIRA, P; DORAY, B. (orgs.). Elementos Para uma Teoria Marxista da Subjetividade. São Paulo: Vértice, p. 11 - 13. 1989. Da alienação ao fetichismo: formas de subjetivação e de objetivação. In: In: SILVEIRA, P; DORAY, B. (orgs.). Elementos Para uma Teoria Marxista da Subjetividade. São Paulo: Vértice, p. $41-76$.

WEBER, M. A. 2003. "objetividade” do conhecimento nas Ciências Sociais. In: COHN, G (org.). Max Weber (Coleção Grandes Cientistas Sociais) $7^{\text {a }}$ Ed. São Paulo: Ática, p. 79 127. 